\title{
Conceptualización del procesamiento digital de imágenes para la evaluación de superficies de pavimento en Costa Rica
}

\section{Conceptualization of the digital image processing for the assessment of pavement surfaces in Costa Rica}

\section{Luis Diego Herra Gómez}

Unidad de Auditoría Técnica, LanammeUCR

Universidad de Costa Rica. San José, Costa Rica

luis.herragomez@ucr.ac.cr

Fecha de recepción: 14 de febrero de 2018 / Fecha de aprobación: 03 de mayo de 2018

\section{RESUMEN}

La atención oportuna de un sistema de carreteras mediante actividades de mantenimiento rutinario, como la construcción de baches y el sellado de grietas, es una práctica reconocida por su buena relación costobeneficio, al evitar que el pavimento se deteriore aceleradamente por el efecto del clima y del tránsito, reduciendo la necesidad de realizar intervenciones mayores y costosas.

Sin embargo, pese a que las actividades de mantenimiento rutinario pueden ser muy beneficiosas, en Costa Rica, identificar los puntos en carretera que requieren ser atendidos mediante este tipo de intervenciones es una labor que está sesgada al criterio de quien realiza la auscultación visual de deterioros, y dependiendo de la ruta que está siendo evaluada podría ser una actividad peligrosa en términos de seguridad vial y seguridad ciudadana si se consideran zonas de riesgo social.

Ante este panorama, se requiere contar con procesos automatizados que permitan generar un inventario de necesidades de mantenimiento de una manera ágil, objetiva y segura. Para ello, actualmente existen diversas alternativas que permiten automatizar el recuento de necesidades de mantenimiento preventivo de una carretera, siendo el procesamiento digital de imágenes una de las más útiles para este fin.

El procesamiento digital de imágenes permite, mediante el uso de algoritmos aplicados a un registro fotográfico de la carretera, definir criterios de intervención para las actividades de mantenimiento rutinario Lo anterior, con el objetivo de identificar con mayor certeza los deterioros bajo cierto umbral de severidad presentes en una carretera.

De este modo, el registro digital de imágenes podría considerarse como un insumo muy valioso para mejorar la eficiencia en cuanto a la inversión ejecutada en un determinado sistema de carreteras, sin olvidar que este tipo de herramientas constituyen un complemento que no debe reemplazar el criterio técnico de los profesionales a cargo delagestión del sistema.

\section{ABSTRACT}

The timely attention of a road system through minor maintenance activities, such as potholes repair techniques and crack sealing, is a practice recognized for its good cost-benefit ratio, by preventing the pavement from an accelerated deterioration dueto the effect of climate and transit, reducing the need of major and expensive interventions.

However, although minor maintenance activities can be very beneficial, in Costa Rica, identifying road segments that requirethesetypes of interventions is a work that could be biased to the criteriaof those who perform the visual auscultation of deteriorations, and depending on the route that is being evaluated, it could be a dangerous activity in terms of road safety.

Given this scenario, it is necessary to have automated processes that allow generating an inventory of preventive maintenance needs in an agile, objective and safe manner. To do this, there are currently several alternatives that allow automating the count of preventive maintenance needs of a road, being digital image processing one of the most used.

The digital image processing allows, by using algorithms applied to a road photographic record, to define intervention criteria for minor maintenance activities, in order toidentify with greater certainty the deteriorations under a certain threshold of severity present in a road.

In this way, the digital image registry could be considered as a very valuable input to improve efficiency in terms of the investment made in a certain road system, without forgetting that this type of tools are a complement that should not replace the technical criteria of the professionals in charge of the road management system.

KEY WORDS: Road Preservation, Road Assessment, Digital Processing, GPR.

PALABRAS CLAVES: Conservación vial, evaluación de carreteras, procesamiento digital, GPR. 


\section{INTRODUCCIÓN}

El presente artículo muestra una revisión bibliográfica enfocada a la aplicación práctica del procesamiento digital de imágenes para el registro de necesidades de mantenimiento rutinario en una red vial. Además, en este documento se abarcan los principales aspectos que caracterizan al esquema de conservación vial para la atención del sistema de carreteras en Costa Rica. A partir de las características de este modelo de conservación, se recuerda la necesidad que tiene el estado costarricense por mejorar su red vial mediante soluciones eficientes que involucren el menor gasto posible.

La atención oportuna de un sistema de carreteras es un aspecto fundamental en la labor de gestión de un sistema de pavimentos, pues el hecho de atender deterioros que están en una etapa prematura, como grietas y baches pequeños, permite evitar un deterioro acelerado de la estructura de pavimentos, y como consecuencia la necesidad de realizar una mayor inversión para restablecer la condición inicial de la carretera. Esta tendencia se ilustra en la Figura 1, que corresponde a la curva de deterioro teórica de un pavimento. Dicha curva muestra los costos relativos de inversión asociados a la recuperación de la condición de una carretera tanto en etapas tempranas de su deterioro, como cuando la condición del pavimento es tal que requiere de una rehabilitación, evidenciando que en un periodo de tiempo relativamente corto los costos de atención de una carretera se pueden aumentar significativamente.
La información que se genera a partir de las evaluaciones de pavimentos es el eje central de la gestión de un sistema de carreteras, pues constituye un insumo fundamental para la toma de decisiones (Rodríguez, 2014). Reconociendo la importancia que tiene la atención de un pavimento en etapas tempranas de su deterioro, se muestra el procesamiento digital de imágenes como un complemento valioso para que la red vial costarricense sea atendida de forma eficiente.

\section{CONTEXTO COSTARRICENSE EN EL MANTENIMIENTO Y EVALUACIÓN DE PAVIMENTOS}

El sistema de carreteras representa uno de los activos más importantes con los cuales puede contar un Estado, y se constituye como un actor clave para el progreso, al permitir el traslado de bienes, personas y la oferta servicios en beneficio del desarrollo socioeconómico de una región. En Costa Rica, el sistema de carreteras, más conocido como red vial nacional, permite conectar a las regiones más alejadas del país con las principales ciudades, siendo la red vial costarricense una de las más densas de América (Loría Salazar et al., 2014).

Esta condición trae consigo una serie de beneficios desde el punto de vista socioeconómico, pues dicha red permite conectar fácilmente las zonas productivas y turísticas con los centros poblacionales más concurridos. Sin embargo, si mantener un sistema de

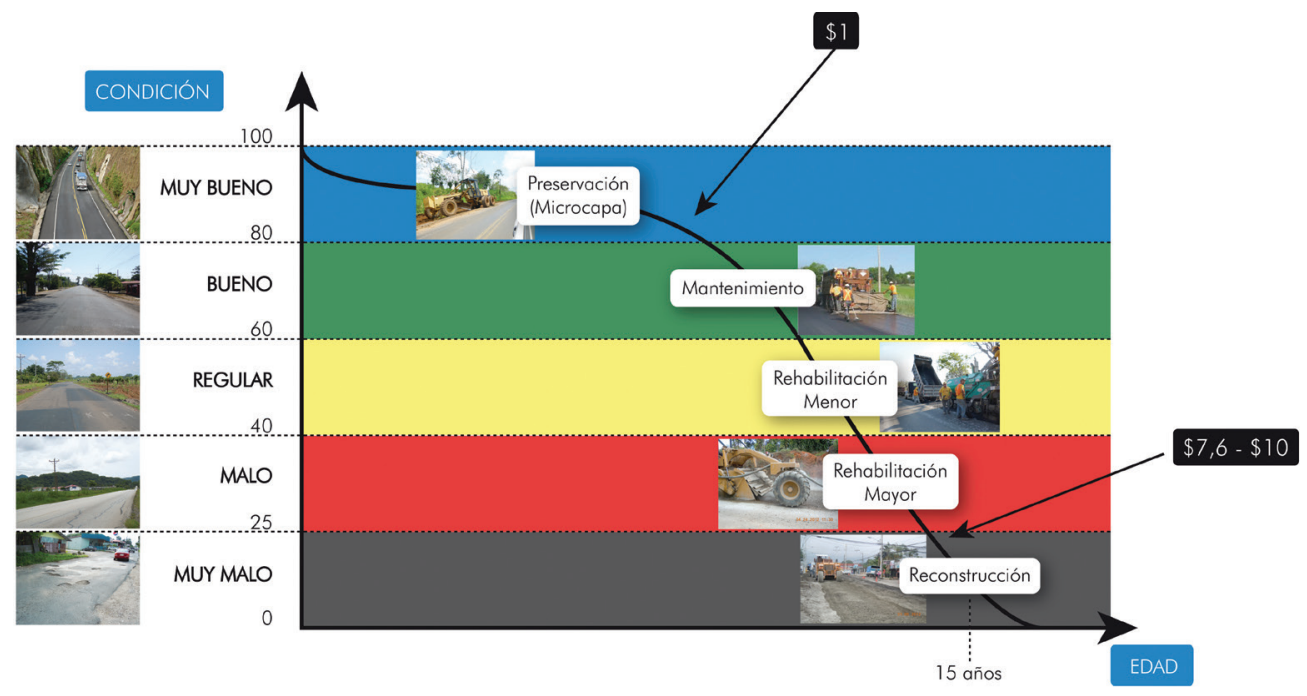

Figura 1. Curva de deterioro de los pavimentos flexibles y los costos relativos de su intervención calibrada a las condiciones de Costa Rica

(Rodríguez, 2014) 
carreteras es una actividad costosa, el hecho de contar con una red vial densa exige un reto para los tomadores de decisiones del sector transporte en Costa Rica, quienes cuentan con un presupuesto limitado para atender estas actividades de mantenimiento.

Actualmente, el esquema de conservación vial en Costa Rica se basa en el pago por actividades mediante precios unitarios, donde empresas privadas concursan para optar por el mantenimiento de una de las 22 zonas de conservación que componen al país. Cada una de estas zonas tiene definido un listado de actividades para el mantenimiento vial según sus características, por ejemplo: construcción de muros de retención, colocación de sobrecapas asfálticas, construcción de baches, tuberías, entre otros; cuyo precio y unidad de pago fueron acordados con la Administración previo al inicio de cada contrato.

Ahora bien, como este sistema de contratación se basa en precios unitarios, el contratista usualmente solo se preocupa por ejecutar las actividades que la Administración le solicite. Bajo este esquema, la Administración debe asumir la tarea de identificar cuáles tramos de la red vial requieren ser intervenidos, así como la magnitud de estas inversiones. De este modo, si se tiene en cuenta que el recurso humano disponible por el Estado para el registro de necesidades en la red vial es escaso, surge la necesidad de contar con apoyo técnico adicional, es acá donde aparece un tercer actor en el sistema de conservación vial costarricense: los administradores viales.

Los administradores viales son empresas contratadas por el Estado con el propósito de que estos sean un apoyo para la Administración en cuanto al registro de necesidades y supervisión de las actividades realizadas por los contratistas asignados a cada una de las 22 zonas de conservación vial. De esta forma, para definir la estrategia de inversión en el mantenimiento de la red vial nacional, la Administración cuenta con el apoyo de los administradores viales y como insumo adicional cuenta con informes de evaluación de la red vial nacional emitidos bienalmente por el Laboratorio Nacional de Materiales y Modelos Estructurales (LanammeUCR).

Estos informes de evaluación categorizan en términos de fricción superficial, de regularidad superficial y desde un punto de vista estructural la condición del sistema de carreteras en Costa Rica, sugiriendo estrategias de intervención de acuerdo con el estado de cada una de las rutas que componen la red. Lo anterior, le ha permitido a la Administración tener claridad sobre el panorama general de las carreteras en el país y las necesidades de cada ruta en términos de la magnitud de la intervención que conviene realizar, ya sean actividades de mantenimiento rutinario, colocación de una sobrecapa, rehabilitación, o incluso si es necesaria, una reconstrucción de la carretera.
Para los casos en que la condición de la ruta amerita una reconstrucción, rehabilitación o sobrecapa, la definición del alcance de las intervenciones está sujeta a un diseño formal, que toma en cuenta variables como las características de los materiales existentes, importancia de la ruta y condiciones climáticas de la zona, que permiten definir con detalle la magnitud de las obras. Por otra parte, cuando la condición de la ruta es relativamente buena y solo se requiere de actividades de mantenimiento rutinario, los administradores viales son los que, mediante auscultaciones visuales, sirven de apoyo para la Administración, sugiriendo estrategias de intervención como la colocación de sellos de grietas, construcción de baches, entre otros.

Con el objetivo de brindar una herramienta que lograra homogenizar y sistematizar los criterios de auscultación para el diagnóstico imparcial, objetivo y técnicamente sustentado de la evaluación de los pavimentos flexibles y rígidos en Costa Rica (LanammeUCR 2012), el Ministerio de Obras Públicas y Transportes (MOPT) oficializó el Manual de auscultación visual de pavimentos de Costa Rica (MAV-2016).

Sin embargo, pese a que la oficialización del MAV-2016 representó un gran avance en aras de reducir el criterio subjetivo a la hora de realizar un levantamiento de deterioros, el proceso de auscultación visual llevado a cabo para determinar las necesidades de mantenimiento rutinario de una carretera es tedioso y en muchas rutas resulta peligroso en términos de seguridad vial. Adicionalmente factores climáticos y zonas de riesgo social aumentan el sesgo y la inseguridad de quien realiza las auscultaciones visuales provocando que exista cierto margen de error asociado a la selección óptima de estas actividades de mantenimiento. Por lo tanto, con tal de optimizar las estrategias de intervención a la red vial costarricense, surge la necesidad de automatizar los procesos de identificación de deterioros menores mediante técnicas ágiles, eficientes y objetivas, siendo la técnica del procesamiento digital de imágenes una de las alternativas más utilizadas para tal propósito.

\section{PROCESAMIENTO DIGITAL DE IMÁGENES PARA LA EVALUACIÓN DE SUPERFICIES DE PAVIMENTO}

La utilización de las diferentes regiones del espectro electromagnético ha permitido reunir información sobre un mismo objeto en una gran variedad de formas, que van desde fotografías hasta imágenes térmicas. El uso de esta información constituye un insumo muy valioso que ha permitido el avance tecnológico de diversas profesiones, tales como la medicina -con la implementación de rayos $\mathrm{x}^{-}$, y la geología -con el uso de termografía infrarroja 
para la detección de planos de falla- (Schnebele et al., 2015). Para la detección de deterioros superficiales en pavimentos también es frecuente el uso de las distintas regiones del espectro electromagnético, siendo el espectro visible, con el recuento de imágenes digitales, una de las regiones más utilizadas para tales fines de evaluación.

Las imágenes digitales se pueden considerar como funciones $\mathrm{f}(x, y)$ que han sido discretizadas tanto en coordenadas espaciales como en luminosidad, donde las variables independientes $x, y$ representan una ubicación y el valor de f para cualquier par $(x, y)$ permite determinar la luminosidad (o nivel de gris) de la imagen en dicho punto. Así, una imagen puede ser considerada como una matriz cuyas filas y columnas identifican un punto en la imagen, y el correspondiente valor de cada uno de estos puntos (también llamados pixeles) permite identificar el nivel de gris correspondiente (Escalante, 2006).

Los métodos de procesamiento digital de imágenes son técnicas que, al considerar el componente numérico de una fotografía, y mediante la aplicación de algoritmos de segmentación, permiten convertir una imagen digital en otra, donde se resalte cierta información de interés, atenuando o eliminando aspectos irrelevantes de la imagen según el tipo de aplicación que se esté llevando a cabo (Alvarado, 2012).

El procesamiento digital de imágenes es un campo de investigación abierto, cuyo constante progreso ha requerido de una integración multidisciplinaria entre diversos campos como la computación, las matemáticas y la medicina, ya que la inquietud del ser humano por imitar ciertas funciones bilógicas del cuerpo humano que intervienen en la precepción y manipulación de imágenes, ha sido uno de los principales motivos que han impulsado el origen de esta técnica (Escalante, 2006).

El sistema visual humano, por ejemplo, puede inferir que los objetos continuos existen incluso cuando su apariencia visual está distorsionada por la presencia de otros objetos en la escena visual o por la ausencia de líneas o contornos en el objeto percibido. Dada la imagen de la Figura 2, resulta casi inevitable observar una disposición de círculos y triángulos. Sin embargo, no hay círculos o triángulos completos en la imagen, en lugar de ello, partes de estas formas están dispuestas de tal manera que la mente tiene que inferir para construir objetos perceptuales continuos (Kast, 2012).

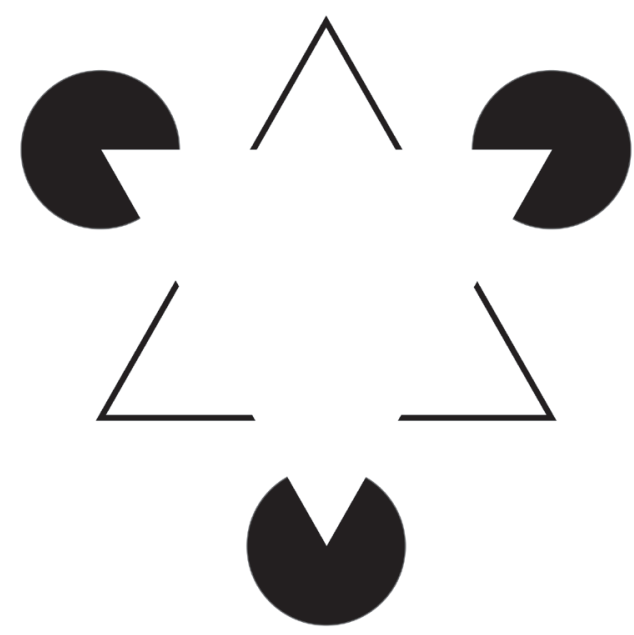

Figura 2. Triángulo de Kanizsa

(Kast, 2012)

Por lo tanto, el cerebro humano está dotado con la capacidad de reconocer patrones en presencia de información sensorial excesiva, que generalmente contiene abundante "ruido" y lo que busca es maximizar la percepción de las señales al tratar de eliminar o atenuar estos elementos que no se consideren importantes (Kast, 2012). Siguiendo esta analogía, el procesamiento digital de imágenes en la detección de deterioros superficiales en pavimentos lo que busca es sacar de contexto aquellas partes de la carretera que se encuentren en buen estado, con el propósito de analizar con mayor facilidad las áreas que requieren de algún tipo de intervención.

\section{Etapas del Procesamiento Digital de Imágenes}

En la Figura 3 se ilustran las etapas a seguir para llevar a cabo el procesamiento digital de imágenes.

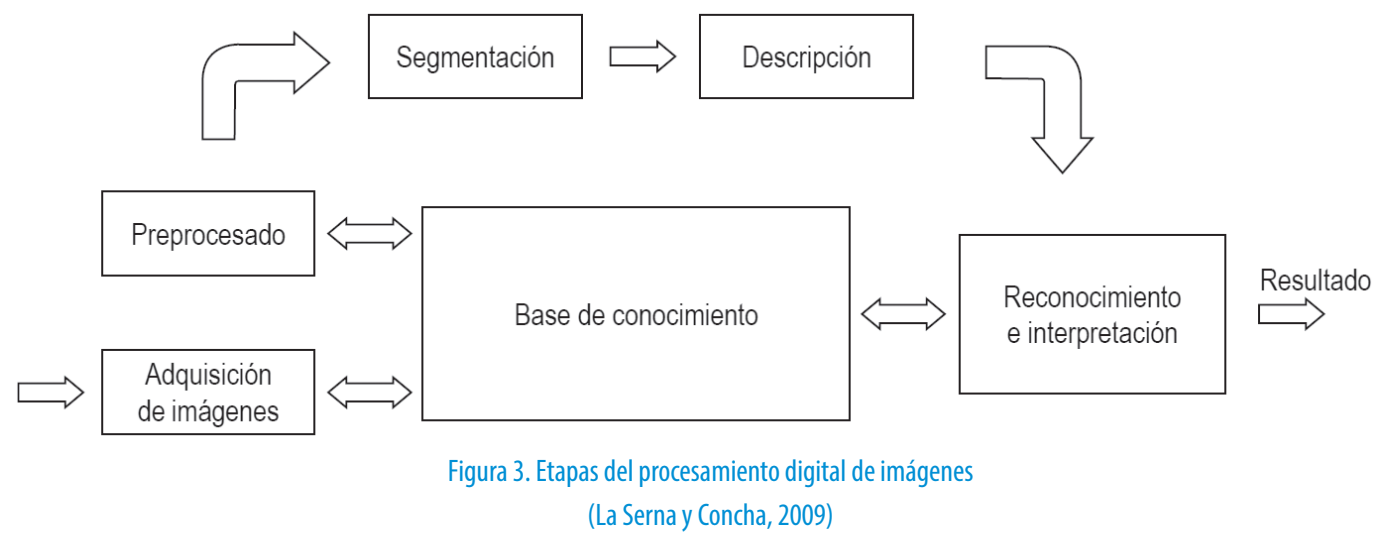


Como punto de partida, se requiere adquirir las imágenes que serán procesadas y analizadas. Para propósitos de identificación de deterioros superficiales en una carretera, los vehículos de reconocimiento son una herramienta muy valiosa, pues permiten mediante un registro continuo (imágenes o video), capturar rápidamente múltiples deterioros presentes en el pavimento. En Costa Rica, el LanammeUCR cuenta con el “Geo3D (Trimble)", herramienta que permite cumplir de manera eficiente con esta primera etapa del procesamiento digital de imágenes (adquisición de imágenes georreferenciadas).

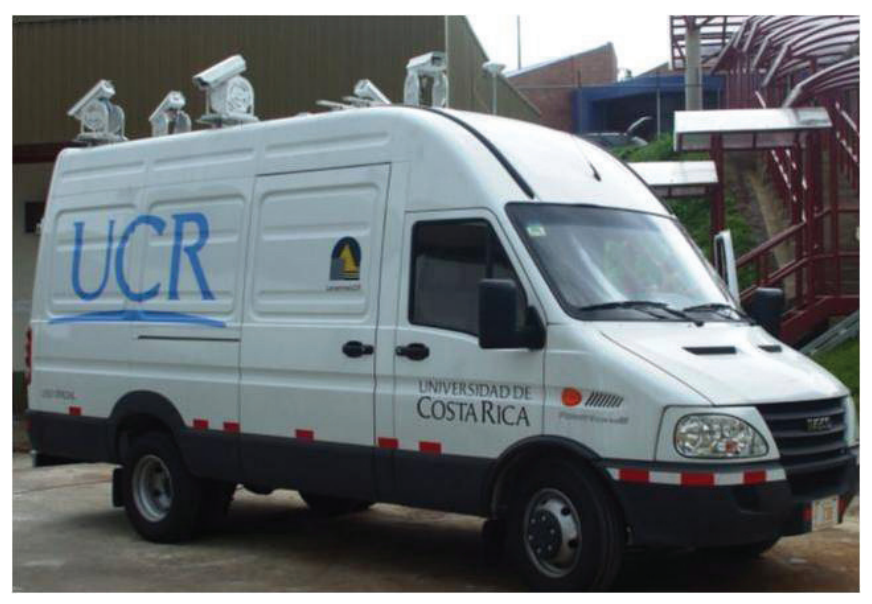

Figura 4. Ge03D propiedad del LanammeUCR

\section{Mejora de Imágenes Digitales (Preprocesamiento)}

Esta etapa se realiza con el propósito de identificar y eliminar aquellas fallas que puedan existir en la imagen, para mejorarla, y que consecuentemente su análisis sea más sencillo (La Serna y Concha, 2009). La aplicación de filtros de mediana es una de las técnicas más utilizadas para la mejora de imágenes de pavimentos. Esta técnica permite homogenizar todos aquellos pixeles de una imagen que cuentan con niveles de gris muy distintos a sus pixeles adyacentes (Ouyang et al., 2011).

Una de las principales ventajas que trae consigo la aplicación de filtros de mediana, es el hecho de que esta técnica permite mejorar la imagen sin la necesidad de eliminar sus bordes o principales rasgos, permitiendo su posterior análisis (Chandel y Gupta 2013). Adicionalmente, a pesar de que el fundamento teórico de esta técnica puede ser complejo, actualmente hay muchos programas computacionales que permiten realizar este trabajo a partir de funciones preprogramadas. Por ejemplo, el software MathLab mediante el comando "medfilt2(A)" permite establecer filtros de mediana generando resultados como los que se detallan en la Figura 5, donde se muestra una imagen cuyos pixeles con una escala de gris significativamente distinta fueron homogenizados con el resto de la imagen sin que se diera una pérdida en los rasgos principales de la fotografía.

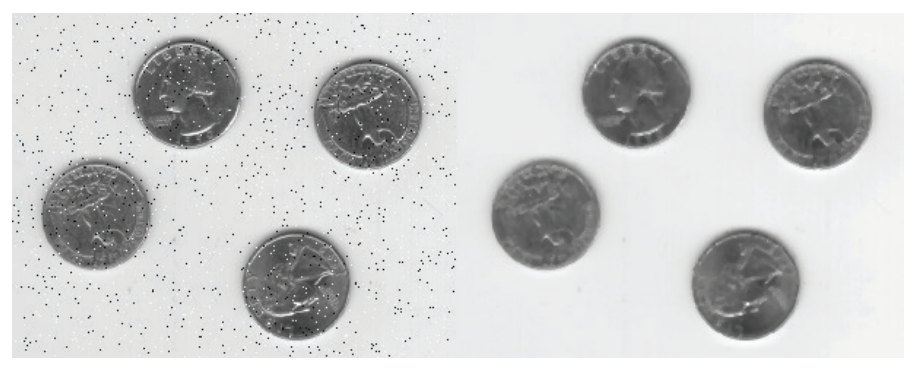

Figura 5. Mejora de imagen digital a partir de filtro de mediana

\section{Segmentación de Imágenes Digitales}

La segmentación de imágenes digitales es el proceso a partir del cual se sacan de contexto aquellas partes de la imagen que no interesan para el análisis, con el propósito de dar énfasis a ciertos aspectos de la fotografía; para ello, hasta el momento se han desarrollado una gran cantidad de algoritmos de segmentación. A continuación, se describe la aplicación de algunos de estos algoritmos para la detección de huecos y grietas en la superficie de carreteras.

Algoritmos para la Detección de Bordes: Un borde se puede considerar como el conjunto de pixeles que existe entre dos secciones homogéneas de una imagen. A lo largo del borde, la función $f(x, y)$ que describe a una fotografía experimenta un cambio en su valor de escala de grises (Alvarado, 2012), de modo que matemáticamente estos cambios pueden ser detectados y aislados usando derivadas de primer y segundo orden.

En la identificación de deterioros superficiales de una carretera, el uso de algoritmos de borde se ha vuelto una práctica común, puesto que el trazo de una grieta superficial constituye por sí misma un borde. La Figura 6 muestra una imagen de una grieta procesada a partir de un filtro de mediana, que posteriormente con la aplicación de un algoritmo de borde fue separada del resto de la carretera.
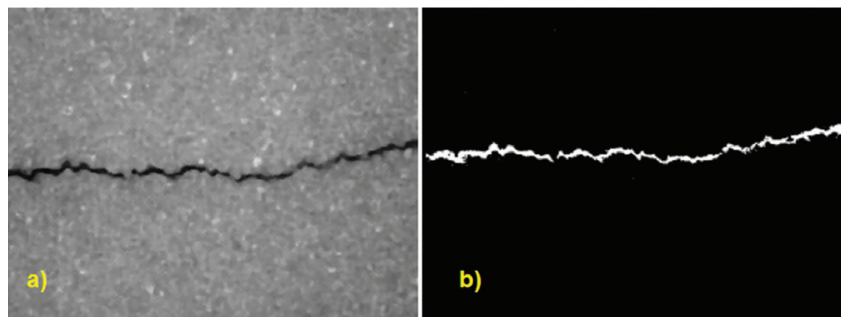

Figura 6. Grieta procesada a partir de un filtro de mediana y posteriormente a partir de un algoritmo de borde

(Ouyang et al., 2011)

La detección de huecos requiere de técnicas como la umbralización para poder ser cuantificados de manera automatizada, debido a que por sus características geométricas el uso de algoritmos de borde no es suficiente. 
Umbralización: Este es uno de los métodos más importantes de la segmentación de imágenes, ya que permite, a partir condiciones aplicadas a los valores de intensidad de gris que componen a una imagen, extraer áreas de una fotografía. Por ejemplo, si se define $f(x, y)$ como la imagen original, $g(x, y)$ como la imagen umbralizada y 125 como el valor umbral medido en nivel de gris, es posible a partir de la ecuación (1) extraer el óvalo negro mostrado en la Figura 7.

$$
\left\{\begin{array}{c}
g(x, y)=255 \text { si } f(x, y) \geq 125 \\
g(x, y)=0 \text { si } f(x, y)<125
\end{array}\right.
$$

Donde un valor de intensidad de gris de cero se asocia con el color negro y valores de 255 con el color blanco.

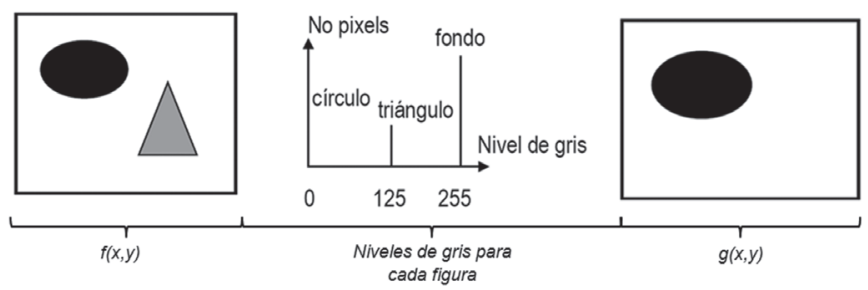

Figura 7. Ejemplo de segmentación mediante umbralización (La Serna y Concha, 2009)

De forma análoga al ejercicio mostrado, es posible mediante algoritmos de umbralización identificar de manera automatizada huecos en la superficie de un pavimento. Por ejemplo, Koch et al. (2013), a partir del uso de algoritmos para la detección de borde y umbralización, logró identificar satisfactoriamente la ubicación de huecos en una superficie de pavimentos, obteniendo los resultados que se muestran en la Figura 8.

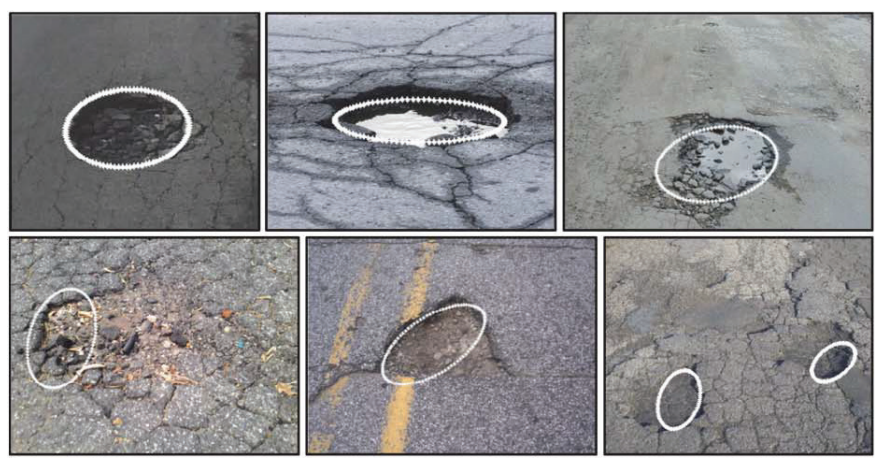

Figura 8. Detección de huecos a partir de algoritmos de detección de borde y umbralización (Koch et al., 2014)
De acuerdo a lo anterior, al emplear la información que se pueda generar de la etapa de segmentación es posible caracterizar los deterioros encontrados, desarrollar bases de datos con un registro de necesidades de mantenimiento y a partir de ello establecer criterios de intervención que le permitan a la Administración costarricense mejorar la eficiencia en cuanto a la inversión que realiza a la red vial nacional.

\section{CONCLUSIONES}

El esquema de conservación vial costarricense, por sus características que se basan en un sistema de precios unitarios, hace requerir a la Administración estatal de un método de auscultación de deterioros eficiente y objetivo que le permita atender pequeños deterioros en el sistema de carreteras de manera oportuna.

En aras de brindar una alternativa que permita identificar este tipo de deterioros, el presente artículo introduce la técnica del procesamiento digital de imágenes. Esta técnica, al permitir identificar deterioros superficiales desde un vehículo en movimiento presenta ciertas ventajas, como la rapidez en el levantamiento de información y la reducción del riesgo a la seguridad vial y la probabilidad de ocurrencia de un asalto en zonas socialmente vulnerables asociada a tener un inspector recorriendo la carreta a pie para observar la condición superficial de la carretera.

Además, el procesamiento digital de imágenes ha sido una técnica ampliamente utilizada en diversos campos de aplicación profesional. Por lo tanto, posee un amplio respaldo y diversas variantes que podrían ayudar a identificar diversos tipos de deterioro en carretera.

En Costa Rica, instituciones como el LanammeUCR cuentan con el recurso material y humano necesario para implementar esta técnica de auscultación visual en la evaluación de la condición de las carreteras.

El fundamento matemático que hay detrás del procesamiento digital de imágenes puede ser complicado; sin embargo, como esta técnica se usa en varios campos de aplicación profesional, la teoría detrás de esta técnica está bien documentada y se cuenta con experiencias de su aplicación para distintos fines.

Por último, pese a las ventajas que conllevan el uso de técnicas como el procesamiento digital de imágenes, se debe tener claro que dicha herramienta hasta el momento no puede sustituir el criterio de un profesional en el área, sino que más bien este tipo de herramientas deben funcionar como un complemento para la toma de decisiones. 


\section{REFERENCIAS}

1. Alvarado Moya, J. P. (2012). Procesamiento y Análisis de Imágenes Digitales. Cartago: Instituto Tecnológio de Costa Rica.

2. Ávila Esquivel, T. Rodríguez Castro, E. Barrantes Jiménez, R. Castro Herrera, J.A. Allen Monge, J. Arriola Guzmán, R., Sequeira Rojas, W. (2012). Manual de auscultación visual de pavimentos de Costa Rica. San Pedro: Universidad de Costa Rica.

3. Chandel, R., \& Gupta, G. (2013). Filtering algorithms and techniques. International Journal of Advanded Research in Computer Science and Software Engineering, 198-202.

4. Escalante Ramírez, B. (2006). Procesamiento digital de imágenes. Distrito Federal, México: Universidad Nacional Autónoma de México.

5. Kast, R. (2012). Knowing Neurons. Recuperado el 11 de noviembre de 2017, de http://knowingneurons.com/2012/12/19/chords-of-perception/

6. Koch, C., Jog, G., \& Brilakis, I. (2013). Automated Pothole Distress Assesment Using Pavement Video Data. Journal of Computing in Civil Engineering, 370-378.

7. La Serna Palomino, N., \& Concha, U. (2009). Técnicas de segmentación en procesamiento digital de imágenes. Revista de ingeniería de sistemas de informática, 9-16.

8. Loría Salazar, G., Barrantes, R., Jiménez, D., Lezama, V., Morales, M., Rodríguez, J. D., y otros. (2014). Vigésimoprimer informe de estado de la nación en desarrollo humano sostenible: Implicaciones en infraestructura y transporte. San Pedro, Monstes de Oca: Estado de la Nación.

9. Ouyang, A., Luo, C., \& Zhou, C. (2011). Surface distresses detection of pavement based on digital image processing. Computar and Computing Technologies in Agricultures IV, 368-375.

10. Rodríguez Morera, J. D. (2014). La auscultación de pavimentos a nivel de red y su importancia en la gestión de carreteras. San Pedro: LanammeUCR, Universidad de Costa Rica.

11. Schnebele, E., Tanyu, B. F., Cervone, G., \& Waters, N. (2015). Review of remote sensing methodologies for pavement management ans assesment. Springer, 0-19. 